\title{
Eventos sustentáveis: um novo ambiente para a comunicação
}

\author{
Sustainable events: \\ a new environment for communication
}

\begin{abstract}
Ana Maria Malvezzi de Souza
Mestre em Comunicação pela Universidade de São Caetano do Sul, possui especialização em Comunicação Empresarial (ESPM) e Psicopedagogia (Universidade Gama Filho). Graduação em Comunicação Social-Jornalismo pela Universidade Católica de Santos (1987). Desde 1993 é professora titular do Centro Universitário Monte Serrat-Unimonte e a partir de 2015 também na Unip.
\end{abstract}

\section{Gino Giacomini Filho}

Possui graduação em Publicidade e Propaganda pela Universidade de São Paulo (1979), mestrado em Ciências da Comunicação pela Universidade de São Paulo (1986), doutorado (1989) e Livre-docência (1995) em Publicidade e Propaganda pela USP. Atualmente é docente da graduação em Comunicação Social da Universidade de São Paulo. Tem experiência acadêmica e profissional na área de Comunicação Social atuando principalmente nos seguintes temas: publicidade e propaganda, responsabilidade social, comunicação, marketing, turismo, consumerismo, atendimento ao consumidor.

\section{RESUMO}

Este artigo, de âmbito exploratório, objetiva oferecer uma visão geral sobre a sustentabilidade ambiental de eventos e estudo comparativo de normas correlatas. Os resultados apontam que as normas ABNT/ISO e ASTM estipulam exigências distintas quanto à certificação de sustentabilidade de eventos acerca dos aspectos relacionados com a comunicação e o meio ambiente.

Palavras-chave: comunicação organizacional; eventos sustentáveis; normas para eventos.

\section{ABSTRACT}

This article, as an exploratory approach, aims to offer a general vision about the environmental sustainability of events and comparative study of correlated standards. The results point that ABNT/ISO and ASTM standards indicate distinctive duties about the certification of events sustainable under the communication and environment aspects. Keywords: organizational communication; sustainable events; events standards. 


\section{Introdução}

A indústria de eventos mostra relevância, sobretudo com o expressivo investimento no setor. Segundo um levantamento do MPI Brasil (Meeting Professional Internacional) sobre o ano de 2012, o setor de eventos faturou $\mathrm{R} \$ 70$ bilhões, num mercado que representa cerca de 3\% do produto interno bruto brasileiro ${ }^{1}$.

Os eventos conduzidos por instituições ou organizações constituemse como um dos procedimentos de comunicação que empresas, associações e entidades utilizam para apresentar produtos, ideias, inovações, experiências e acontecimentos para diversos públicos (SACHUK; CORREA, 2007).

Ao impactar diferentes stakeholders, e face à inserção em um contexto competitivo, faz-se necessário que cada evento seja sustentável, caso de atender aos requisitos referentes ao meio ambiente (FONTES et al, 2008). Os eventos causam impactos ambientais envolvendo elementos como emissão de gases poluentes, aumento do consumo de água, produção de resíduos sólidos e consumo de energia. Desde 2012, com a organização das Olimpíadas de Londres e a edição da ISO 20121, as normas sobre a sustentabilidade para os eventos ganharam destaque.

Este estudo pretende oferecer uma visão geral sobre a sustentabilidade ambiental de eventos, além de análise comparativa das normas ABNT NBR ISO 20121 e ASTM E60.02 quanto às dimensões ambientais e de comunicação.

A pesquisa foi desenvolvida em nível exploratório com revisão bibliográfica envolvendo os eixos temáticos de eventos e meio ambiente, e normas para eventos no plano ambiental, abordando também as questões de comunicação do evento. Foi desenvolvida pesquisa documental com análise do conteúdo pautada pelo modelo de Laurence Bardin (2004). Os documentos em questão consideraram dois sistemas normativos: a) sistema ISO, do qual integra a norma da ABNT (Associação Brasileira de Normas Técnicas), ou seja, a ISO 20121 (Sistema de Gestão para Sustentabilidade de Eventos); b) sistema ASTM E60.02, elaborado pela American Society for Testing and Materials. Além da análise, houve uma abordagem comparativa entre as normas a fim de se obter um entendimento sobre a dimensão das mesmas e, assim, enriquecer os resultados da pesquisa.

\section{Eventos sustentáveis: foco no meio ambiente.}

Equilibrar interesses da sociedade com os da empresa é um intento presente nas estratégias de comunicação organizacional, algo que está tipicamente a cargo da área de relações públicas. Os eventos podem estar inseridos no plano de negócio, marketing e relações públicas, mas devem se harmonizar com os propósitos da organização. As ações de planejamento, portanto, devem considerar o fato de que um evento é componente e extensão da imagem organizacional, devendo atentar-se para todos os efeitos e desdobramentos desde a fase de elaboração, caso daqueles que impactam pessoas, 
comunidade e sociedade. Dessa forma, os eventos ganham contornos de atividade ou produto estratégico, inclusive no escopo da responsabilidade social e do desenvolvimento sustentável.

Fortes e Silva (2011) descrevem as relações públicas em diferentes modelos e inserem os eventos no grupo de veículos de comunicação dirigida aproximativa, como elemento fundamental no mix da comunicação. Destacam a área de eventos como "o contato direto entre um grupo de interesse, ou seja, uma organização, e diversos outros grupos com os quais uma instituição deseja ou precisa se comunicar" (FORTES; SILVA, 2011, p. 33).

Há uma grande variedade de eventos, tais como fórum, simpósio, seminário, painel, congresso, convenção, palestra, jornada, colóquio, conferência, debate, desfile, exposição, feira, oficina, salão, semana, workshop, lançamentos, alguns também no formato virtual ou não presencial. "Mediante essa variedade de eventos, as empresas têm a oportunidade de atingir seu público-alvo, buscando sempre apresentar inovações [...]" (SACHUK; CORRÊA, 2007, p. 46).

O processo de comunicação está presente na organização atendendo continuamente, mas seletivamente, as necessidades de informação, negociação, persuasão mediante diferentes stakeholders. Nesse contexto, as empresas proporcionam conteúdos e espaços de diálogo interativo com pessoas e grupos a fim de estabelecer novas relações ou mantê-las usando diferentes meios, caso do website institucional, campanhas promocionais, formatos jornalísticos e os próprios eventos. São procedimentos que, devidamente articulados, aproximam os públicos das realizações da organização, dentre eles os que se relacionam com as políticas ambientais e de sustentabilidade.

Monzoni-Neto et al (2011) consideram eventos sustentáveis aqueles que atingem seu objetivo de maneira financeiramente viável, causando o menor impacto possível ao meio ambiente e propiciam melhorias na distribuição de oportunidades e geração de riqueza para a população local.

Os impactos ambientais dos eventos podem ser considerados quanto à poluição sonora, geração de resíduos sólidos, captação e descarte de água, aumento no fluxo de trânsito de veículos no entorno e muitos outros. Um exemplo seriam os impactos com o evento da Copa do Mundo no Brasil em 2014 em que é esperada, apenas com as viagens aéreas, a emissão de dióxido de carbono equivalente a 560 mil carros ao longo de um ano ${ }^{2}$.

Eventos e, principalmente, megaeventos podem causar impactos de curto e longos prazos tanto nas comunidades quanto nos demais stakeholders (mídia, participantes, comunidade do entorno, patrocinadores), havendo necessidade de um equilíbrio entre as necessidades, expectativas e interesses de todos os impactados e a entidade organizadora.

Tais impactos integram-se plenamente ao escopo da responsabilidade social organizacional, pois sinaliza a preocupação das organizações em combinar eficiência e lucro com valores de cidadania, preservação ambiental e ética nos negócios.

Entre os diferentes tipos de eventos, Matias (2013) inclui o termo "megaevento" exemplificando com os jogos olímpicos e as feiras mundiais, acontecimentos que podem gerar consequências socioambientais e de longa duração para as cidades que os sediam. Os megaeventos, quando ofertados pela iniciativa privada, demandam uma gestão 
compartilhada com o poder público considerando os impactos que geram nos interesses das comunidades do entorno, de forma que uma gestão responsável e integrada traz um efeito multiplicador que se estende, por exemplo, ao turismo, ao patrimônio cultural e ambiental daquela localidade (O'BRIEN; GARDINER, 2006).

Andersson et al (2013) mencionam inovações que envolveram a comunicação do Way OutWest, um festival de rock, hip-hop e pop music, com duração de três dias, na Suécia. O evento ganhou a reputação de ser ecologicamente correto; seu engajamento com a sustentabilidade ambiental fez com que sua comunicação na edição de 2012 destacasse que, no local, não seriam servidos mais alimentos com carne. Tal postura criou também uma forte discussão com a mídia tradicional, que viu nessa postura uma conduta de restrição aos carnívoros. Como esse assunto teve repercussão nas mídias sociais digitais, alcançou patamares inéditos de forma até a obscurecer o próprio conteúdo do festival. Os autores mencionam que o evento centrou-se na comunicação lastreada numa estratégia vegetariana e que esta foi positiva para agregar valores ambientais aos stakeholders e frequentadores do festival.

A oferta de um evento precisa se associar aos aspectos de sustentabilidade no qual o meio ambiente é um dos focos centrais. Todas as etapas que culminam com a oferta de eventos devem estar ancoradas na minimização dos impactos socioambientais, algo que também pode ser publicizado nas peças e atividades de comunicação.

A divulgação de ações ambientalmente corretas na oferta de um evento compõe-se com um delineamento organizacional sustentável, de forma que é plausível um evento zelar pelas boas práticas ambientais e comunicar aos seus stakeholders tal implementação, até porque o êxito de tais práticas depende dessa interação, principalmente com o público interno.

Avigo (2013) mostra, com elementos práticos, como os eventos corporativos buscam o alinhamento com as estratégias empresariais no cenário da sustentabilidade. A autora destaca "a importância de estabelecer um processo de auditoria e certificação para os eventos que se propuserem a elaborar e implementar um processo sustentável, para que eles se tornem dignos de crédito diante dos clientes" (2013, p. 12). Mas, destaca também a importância de haver uma gestão comprometida em investir em todos os instrumentos do mix de comunicação com diretriz efetivamente sustentável.

\section{Normas para eventos e aspectos ambientais}

Quando uma organização desenvolve um evento com práticas ambientais seguindo normas, principalmente aquelas elaboradas e auditadas por entidades independentes, mostra comprometimento com a qualidade dos resultados e transparência junto aos stakeholders, algo que também agrega credibilidade institucional e legitimidade social ao evento em si. Segundo a International Organization for Standardization ${ }^{3}$, a certificação traz benefícios tecnológicos, econômicos e sociais, dentre os quais ajuda a sociedade a obter produtos e serviços mais seguros, eficientes e adequados ao meio ambiente, de forma que determinadas normas também ajudam a reduzir os impactos 
negativos no plano ambiental.

A qualidade de processos sustentáveis tem como um dos instrumentos globais o Sistema de Gestão Ambiental da ISO 14001, porém existem muitos outros procedimentos normativos e certificadores acerca de processos envolvendo impactos no meio ambiente. Dessa forma, considerando a competitividade e relevância da indústria de eventos, as organizações que tratam de certificação ou elaboração de normas contemplam o setor não somente com a edição de normas acerca da sustentabilidade, mas a atualização e aprofundamento de diretrizes voltadas para o meio ambiente.

Normas para eventos também mostram diversificação: há as que são estipuladas por órgãos públicos e que regulamentam a oferta de eventos no âmbito de prefeituras ou estados; há as que são emitidas e seguidas pelas respectivas entidades sociais e organizações empresariais, havendo até normas elaboradas para conduzir um único evento.

No Brasil, um trabalho normativo para eventos é realizado pela ABEOC BRASIL (Associação Brasileira de Empresas de Eventos) que em parceria com o Sebrae (Serviço Brasileiro de Apoio às Micro e Pequenas Empresas) e tendo como referência o modelo de certificação adotado pela Federação Suíça de Turismo, oferece o Selo de Qualidade ABEOC Brasil; porém tal selo não é para os eventos em si, e sim para micro e pequenas empresas que promovem eventos ${ }^{4}$. A certificação para um evento pode também ser obtida pelo Sistema ISO 9001, que estabelece norma de qualidade para produtos e serviços em quaisquer setores de atividades. Porém, não se apurou no mercado brasileiro uma norma emanada de entidade independente certificadora para eventos como um todo.

No entanto, observa-se a existência de algumas normas, inclusive certificadoras de entidades independentes, voltadas para a sustentabilidade de eventos.

Uma delas é a NBR ISO 20121 (Sistema de gestão para sustentabilidade de eventos) oferecida pela ABNT seguindo o modelo da $\mathrm{ISO}^{5}$.

Outra norma de caráter independente é a ASTM/E60.02 da American Society for Testing and Materials (ASTM), elaborada especificamente pela sua Subcomissão de Sustentabilidade para Hospitalidade (E60.02), versão $2012^{6}$. Essa norma é um conjunto de oito normas ASTM já existentes, cuja proposta é compartilhar a responsabilidade entre os planejadores e fornecedores para fazer um evento mais sustentável. Essas oito normas são:

Especificação para avaliação e seleção para reuniões ambientalmente sustentáveis, eventos, feiras e congressos:

- destino (E2741);

- exposições (E2742);

- transporte (E2743); 
- Ándio visual e produção (E2745);

- Comunicação e materiais de marketing (E2746);

- Escritórios no local (E2747);

- Alimentos e bebidas (E2773);

- Locais (E2774).

As normas ISO/ABNT e ASTM são de adoção de caráter voluntário para as entidades organizadoras de eventos. Apresentam escopo do conteúdo, seu alcance, a amplitude e os respectivos objetivos. Evidenciam também a utilização de outras normas como referência para a respectiva configuração final e publicada.

Com a finalidade de explicitar o âmbito e diferenciações dessas normas quanto à esfera ambiental, empreende-se na sequencia um estudo comparativo de ambas. A comparação de normas é uma maneira de enriquecer a discussão dos conteúdos e das questões apresentadas, uma visão aplicada, prática, que acrescenta valor para ambas as estruturas analisadas (GÖBBELS; JONKER, 2003).

\section{Análise das normas e resultados}

Durante o segundo semestre de 2013, houve a busca por normas certificadoras e de caráter voluntário, aplicáveis a qualquer tipo de evento e estabelecidas por organizações independentes.

Destacaram-se a ISO 20121 (NBR ISO 20121 na versão brasileira) e ASTM/E60.02. Surgiu também a OKS 8012 (do Instituto Oksigeno), norma desenvolvida por uma organização brasileira, mas que, pela pouca abrangência ${ }^{7}$, não foi alvo do estudo comparativo.

Optou-se por fazer um estudo comparativo entre as normas NBR ISO 2012 e ASTM/E60.02. Dessa forma, é possível tanto apresentar conteúdos de ambas como aferir aspectos que as diferenciam para avaliar um evento quer no aspecto de impacto ambiental, quer em termos de uso da comunicação social.

As duas normas, na íntegra, foram adquiridas e se constituíram nos dois documentos alvo da análise de conteúdo. Tendo em vista a viabilização da análise conforme preceitua Bardin (2004), os documentos foram divididos em três grandes categorias: Âmbito da norma, Aspectos ambientais e Aspectos de comunicação.

O "âmbito da norma" compreende o texto introdutório em que constam as referências normativas e o escopo da norma em si. Ou seja, apresenta o objeto que trata a norma e balizamentos conceituais que ela segue.

Já os "aspectos ambientais" se referem aos temas e objetos do meio ambiente contemplados na norma, ou seja, aspectos e elementos que caracterizam o evento como sustentável em termos ambientais. A comparação 
ficou restrita aos aspectos ambientais encontrados nas normas, de forma que não se buscou elementos externos ou não mencionados nas mesmas.

Os "aspectos de comunicação" se referem a elementos do sistema de comunicação (emissor, receptor, meio, mensagem, contextos) ou procedimentos comunicacionais (instrumentos ou formas de comunicação) previstos pela norma a fim de viabilizar os intentos sustentáveis de um evento. Assim como nos aspectos ambientais, os aspectos de comunicação ficaram restritos àqueles encontrados nas duas normas.

Bardin (2004) afirma que a análise de conteúdo possibilita quantificar a frequência de elementos, algo que foi feito para se avaliar a diversidade com que o meio ambiente e a comunicação social são contemplados nas normas. A autora também menciona que tal método permite lidar com conteúdos qualitativos, significados e desdobramentos, algo que é feito de forma sumária dado o tratamento sintético que requer o formato deste artigo.

O Quadro 1 mostra o âmbito geral de cada norma e a aponta que ambas trazem seu escopo e referências normativas. Na ABNT NBR ISO 20121, a finalidade apontada é especificar os requisitos de um sistema de gestão para sustentabilidade de eventos para qualquer tipo de evento ou ações relacionadas a essa atividade. Menciona que a norma foi projetada para tratar da melhoria da gestão de sustentabilidade em todo o ciclo da gestão de eventos. O escopo da ASTM está presente nas oito normas que compõem a E60.02 e delineia requisitos processuais para as especificações a serem avaliadas, buscando a identificação de critérios relacionados à sustentabilidade ambiental. O alvo da certificação, tanto ASTM como ABNT NBR ISO, é a organização na realização do evento. Os dois escopos tratam da gestão de eventos sustentáveis e preveem os processos.

Apesar de constar no início do texto da ABNT/ISO que não há referências normativas, em várias passagens de seu conteúdo há menções a outras normas, como ABNT NBR ISO 26000, ABNT NBR ISO 14001, além de apresentar, no final, uma lista com 14 itens bibliográficos, entre eles a BS 8900 (Guidance for managing sustainable development) criada para as Olimpíadas de Londres. Outro elemento crítico é o formato da norma, pois, apesar de estar previsto que os anexos contemplariam guias e informações para a implementação de eventos sustentáveis, muitas vezes o texto é muito genérico, sem entrar em detalhamentos de formas e números de como realmente realizar um evento sustentável, seja no aspecto ambiental, elementos dos aspectos de comunicação, ou procedimentos práticos.

Já a ASTM optou por não criar uma nova redação em uma única norma e sim compilar várias já existentes, reunidas a partir de uma subcomissão da E60, criando, assim, a E.60.02. Dessa forma, acaba por repetir alguns elementos, como o item sobre terminologias e gestão de resíduos. Por outro 
lado, quando analisa a questão do aspecto da comunicação, a ASTM torna-se mais detalhada, inclusive com percentuais de redução. O Quadro 1 mostra uma síntese das duas normas quanto ao escopo e referências normativas.

\begin{tabular}{|l|l|l|}
\hline \multicolumn{2}{|l|}{ Quadro 1 - Elementos do "Âmbito da norma" } \\
\hline Âmbito da norma & ABNT NBR & ASTM \\
& ISO 20121 & E60.02 \\
\hline Escopo & $\checkmark$ & $\checkmark$ \\
\hline Referências normativas & $\checkmark$ & $\checkmark$ \\
\hline
\end{tabular}

Os aspectos ambientais estão assinalados no Quadro 2 e nas duas normas aparecem questões relativas à qualidade do ar, água, consumo de energia, gestão de resíduos, ocupação e exploração do espaço e configuração da cadeia produtiva. Mas se a norma ASTM contempla apenas $56 \%$ do total de aspectos abordados pela ISO, esta última elenca elementos e fatores adicionais como educação ambiental, impactos no futuro, bem estar animal, ruídos, produtos químicos e matriz de maturidade em relação à sustentabilidade.

Sobre a qualidade do ar, a ISO 20121 sugere a atenção ao sistema de transporte para a compensação das emissões de carbono (CO2), com o incremento do transporte público e a utilização do sistema de caronas para os participantes que vão ao mesmo destino.

Na questão do consumo de energia, além do levantamento da utilização da energia, a ASTM 60.02 inclui a iniciativa de redução da necessidade de consumo nos eventos, a fim do organizador de eventos estabelecer o que é realmente imprescindível.

Ao passar pelo elemento água, além da preocupação das duas normas em analisar a qualidade da água e utilizá-la de forma consciente, a ASTM E60.02 indica a não utilização de água engarrafada a fim de minimizar os efeitos ambientais.

A escolha do local para realização do evento, sobretudo as áreas verdes e a otimização dos espaços, aparecem na preocupação com a biodiversidade prevista na ISO 20121.

A gestão de resíduos vai além da coleta seletiva ou a reciclagem de materiais, pois a ISO 20121 estabelece a prevenção da geração de resíduos, considerando assim um planejamento para a redução do consumo e uso de materiais.

A cadeia produtiva também é contemplada nas duas normas; são abordadas questões práticas que envolvem todos os que atuam antes, durante e após a realização do evento, caso também da preferência por fornecedores locais, não só para privilegiá-los, mas para causar menos impacto como em questões de transporte e logística. A cadeia produtiva diz respeito às 
organizações que participam da oferta do evento, devendo os organizadores desenvolver e aperfeiçoar políticas de aquisição sustentável e manter uma comunicação clara e aberta com os fornecedores.

Além das ações diretas sobre as questões ecológicas, a educação ambiental é elemento integrante nas duas normas analisadas, onde os primeiros a terem essa visão devem ser os envolvidos na organização e execução do evento e, a partir daí, transmitida externamente ao público em geral.

Embora as normas sejam direcionadas a qualquer tipo de evento ou abrangência, as discussões sobre os impactos gerados por essa atividade tem destaque na ISO 20121 no que diz respeito ao legado deixado pelo evento. Esse tópico trata dos recursos de infraestrutura de forma que atenda às necessidades do momento, mas que haja um planejamento para não comprometer o espaço, comunidade e meio ambiente após o término do evento. A ISO 20121 é derivada da norma britânica BS 8901, criada na fase de preparação dos Jogos Olímpicos de Londres, em 2012, com a preocupação sobre as consequências do pós-evento. O resultado do evento está previsto como legado no item 3.19, que inclui os impactos físicos, econômicos, sociais e ambientais duradouros de um evento ou eventos. Abrange, ainda, elementos não materiais, como novas capacidades adquiridas com o evento, os novos conhecimentos, normas, melhores práticas, inovações e contribuições para a sociedade.

A ISO 20121 destaca também as atividades com animais, assegurando situações que propiciem seu bem estar, evitando assim que o evento não coloque em risco significativo qualquer espécie animal.

A matriz de maturidade reporta à gestão do evento no relacionamento com stakeholders, caso de uma abordagem aberta, honesta e transparente. Abarca questões como aspectos educacionais com os stakehoders, lucro sustentável, aplicação de todas as normas pertinentes, treinamento, remuneração adequada, impactos ambientais derivados da gestão. O modelo da matriz apresenta os níveis de abordagem como engajado, melhoria e mínimo.

Ainda sobre as questões ambientais, a mesma norma contempla a prevenção do uso de produtos químicos identificados por organismos científicos e também os níveis de ruídos inaceitáveis na comunidade circunvizinha ao evento. Uma síntese dessa análise está no Quadro 2.

\begin{tabular}{|l|l|l|}
\hline \multicolumn{3}{|l|}{ Quadro 2 - Elementos dos “Aspectos ambientais” } \\
\hline Aspectos ambientais & $\begin{array}{l}\text { ABNT NBR } \\
\text { ISO 20121 }\end{array}$ & $\begin{array}{l}\text { ASTM } \\
\text { E60.02 }\end{array}$ \\
\hline $\begin{array}{l}\text { Controle da qualidade do ar } \\
\text { Compensação das emissões de } \\
\text { carbono (CO2) }\end{array}$ & $\checkmark$ & $\checkmark$ \\
\hline Consumo de energia & $\checkmark$ & $\checkmark$ \\
\hline Utilização da água & $\checkmark$ & $\checkmark$ \\
\hline
\end{tabular}




\begin{tabular}{|l|l|l|}
\hline Saneamento & $\checkmark$ & \\
\hline $\begin{array}{l}\text { Escolha do local - Uso dos espaços } \\
\text { e áreas verdes }\end{array}$ & $\checkmark$ & $\checkmark$ \\
\hline Gestão de resíduos & $\checkmark$ & $\checkmark$ \\
\hline $\begin{array}{l}\text { Educação ambiental } \\
\text { Resultado/ Legado deixado pelo } \\
\text { evento }\end{array}$ & $\checkmark$ & $\checkmark$ \\
\hline Cadeia Produtiva & $\checkmark$ & \\
\hline Bem-estar animal & $\checkmark$ & $\checkmark$ \\
\hline Matriz de maturidade & $\checkmark$ & \\
\hline Produtos Químicos & $\checkmark$ & \\
\hline Ruídos & $\checkmark$ & $\mathbf{7}$ \\
\hline Total & $\mathbf{1 4}$ & $\mathbf{1 0 0}$ \\
\hline \% (ABNT x ASTM) & & \\
\hline
\end{tabular}

Os aspectos e elementos de comunicação engendrados nas normas estão assinalados no Quadro 3. Os aspectos de comunicação da ASTM foram retirados da norma E2746 Especificação para Avaliação e Seleção de Comunicação e Materiais de Marketing para Reuniões, Eventos, Feiras e Conferências Ambientalmente Responsáveis, que integra a norma ASTM E60.02. Já os elementos de comunicação na norma ABNT foram retirados do item 7.4 "Comunicação".

As duas normas apreciam tanto o fluxo de comunicação como a divulgação da política de sustentabilidade, que na ABNT prevê o detalhamento do que, quando, a quem e como comunicar. Porém a norma ASTM também aprofunda nos aspectos de redução e reutilização de materiais de identificação e sinalização, como o consumo de papel, reutilização de suportes de sinalização, redução ou até mesmo eliminação de brindes promocionais em toda a comunicação estabelecida com os stakeholders na cadeia produtiva.

A solução em substituir os impressos por arquivos eletrônicos também compõe a E60.02, onde estão previstos recursos como fornecer os registros e publicações on-line.

\begin{tabular}{|l|l|l|}
\hline \multicolumn{3}{|l|}{ Quadro 3 - Elementos dos “Aspectos de comunicação” } \\
\hline Aspectos de comunicação & $\begin{array}{l}\text { ABNT } \\
\text { NBR ISO } \\
20121\end{array}$ & $\begin{array}{l}\text { ASTM } \\
\text { E60.02 }\end{array}$ \\
\hline Fluxos de comunicação & $\checkmark$ & $\checkmark$ \\
\hline $\begin{array}{l}\text { Substituição de impressos por arquivos } \\
\text { eletrônicos como formatos de } \\
\text { comunicação. }\end{array}$ & & $\checkmark$ \\
\hline
\end{tabular}




\begin{tabular}{|l|l|l|}
\hline $\begin{array}{l}\text { Divulgação da política de } \\
\text { sustentabilidade para os stakeholders }\end{array}$ & $\checkmark$ & $\checkmark$ \\
\hline $\begin{array}{l}\text { Redução e reutilização de material de } \\
\text { identificação e sinalização }\end{array}$ & $\checkmark$ \\
\hline $\begin{array}{l}\text { Redução, reutilização reciclagem e } \\
\text { descarte de materiais promocionais }\end{array}$ & $\checkmark$ \\
\hline $\begin{array}{l}\text { Comunicação com stakeholders na cadeia } \\
\text { produtiva }\end{array}$ & $\checkmark$ & $\checkmark$ \\
\hline Total & 3 & 6 \\
\hline \% (ABNT x ASTM) & $50 \%$ & $100 \%$ \\
\hline
\end{tabular}

A ISO 20121 trata de forma objetiva sobre o que, quando, a quem e como comunicar, incluindo, quando apropriado, os princípios da organização sobre o desenvolvimento sustentável, os propósitos do evento e o que é relevante para todas as partes interessadas. Trata, ainda, dos métodos de comunicação interna, desde reuniões a instrumentos mais formais, como boletins informativos, intranet, quadro de avisos e procedimentos para comunicações externas, além da preocupação com formatos especiais: braile, dispositivo de telecomunicações para surdos e linguagem de sinais. A ASTM 60.02 delimita, mais especificamente, a redação das políticas de sustentabilidade para os stakeholders, prioriza a divulgação online em vez do formato impresso e destaca que a comunicação não está restrita a divulgação do evento, mas em todos os tipos de material utilizados no processo, como brindes e artigos promocionais, sinalização, materiais educativos, instruções pós-evento a cada expositor em feiras, formulários, embalagens, guias e mapas de eventos e crachás.

A orientação de redução substancial na utilização de papel aparece na ASTM, visando priorizar todo e qualquer tipo de comunicação de forma eletrônica. A ASTM 60.02 indica, inclusive, a troca de cartões em feiras pela captura de dados eletrônicos.

A preocupação em prover informações reais e imparciais são determinantes nas normas e na produção de relatórios, uma vez que as normas visam melhorar a sustentabilidade das atividades relacionadas a eventos.

\section{Considerações finais}

Este trabalho propôs oferecer uma visão geral sobre a sustentabilidade 
ambiental de eventos enfocando a análise das normas ABNT NBR ISO 20121 e ASTM E60.02 quanto às dimensões ambientais e de comunicação. Tal intento foi conduzido pelo referencial teórico que contextualizou os eventos como recurso comunicacional e, no âmbito atual, atrelados a uma política de boas práticas ambientais, com a qual as normas de qualidade podem contribuir.

A gestão ambiental dos eventos está vinculada a uma política de responsabilidade social organizacional e tal procedimento reflete não somente na viabilidade do evento, mas na sua consecução e edições futuras. A relevância socioeconômica da indústria dos eventos no Brasil oferece condições adicionais para que tal setor seja componente importante do sistema organizacional e comunicacional, fazendo com que a oferta e promoção de eventos adotem posturas e ações compatíveis com os modelos de sustentabilidade.

A comunicação está diretamente envolvida com tal fenômeno não apenas pelo caráter comunicacional dos eventos, mas também porque a dinâmica destes depende de estratégias, fluxo, instrumentos e formas de comunicação, elementos estes que também contribuem com o passivo ambiental.

Reportando-se ao método de análise documental, foi empreendida análise das normas certificadoras para eventos sustentáveis ABNT NBR ISO 20121 e ASTM E60.02 para uma posterior comparação entre ambas. Tal procedimento, além de apontar os aspectos ambientais que se relacionam à oferta de eventos, evidenciou que a comunicação é um subsistema para a difusão da sustentabilidade e agente a ser observado quando de análise e ações para se prevenir impactos indesejáveis ao meio ambiente. Dessa forma, parece que a comunicação é tanto elemento ativo com potencial de dano ambiental, como também proativo, no sentido de poder contribuir para a minimização dos impactos e até com a educação ambiental.

Foi possível observar que as duas normas apresentam aprofundamento diferenciado, pois enquanto a norma ABNT NBR ISO 20121 cobre amplo espectro de questões ambientais, a norma ASTM E60.02 é mais completa quanto aos aspectos de comunicação.

A ABNT parece priorizar os procedimentos estratégicos ou holísticos da comunicação - "Fluxos de comunicação"; "Divulgação da política de sustentabilidade para os stakeholders"; "Comunicação com stakeholders na cadeia produtiva" - abstendo-se de inserir formalmente na sua norma aqueles que parecem ser apenas operacionais - "Substituição de impressos por arquivos eletrônicos como formatos de comunicação"; "Redução e reutilização de material de identificação e sinalização"; "Redução, reutilização reciclagem e descarte de materiais promocionais", procedimentos previstos na norma 
ASTM.

Com tal aprofundamento, a norma ASTM parece também se importar com ações que transcendem aspectos funcionais e materiais atrelados às atividades de comunicação, caso de sugerir ações educativas ou que combinem com uma imagem sustentável para o evento. A transição de peças gráficas em papel para o formato eletrônico, por exemplo, talvez não implique em impactos ambientais relevantes, mas a visibilidade proporcionada por essa decisão colabora com os intentos de agregar ao evento um caráter de sustentabilidade tanto na prática como no discurso, tanto em questões maiores como nos detalhes, tanto em termos operacionais como de imagem.

Quando a norma ASTM sugere, inclusive, a eliminação de brindes promocionais na cadeia produtiva, oferece aos profissionais de comunicação um tema peculiar, semelhante ao conceito de consumismo ao qual consumidores e empresários estão acostumados. Isso porque, até então, a redução de materiais promocionais em eventos decorria de necessidades de diminuição de custos ou de decisões operacionais dos organizadores. No entanto, a norma incentiva uma reflexão sobre as ações promocionais não somente em termos de eficácia comunicacional, mas diante das questões de sustentabilidade, o que aproxima tal discussão do combate ao consumismo.

As diferenças nas normas observadas neste estudo permitem sugerir que ambas as entidades - ABNT e ASTM - mantenham contatos para editarem atualizações que possam melhorar o sistema de certificação, de forma que a sociedade, stakeholders e as organizações promotoras de eventos beneficiem-se desse instrumental qualitativo.

Ficou evidenciado que a preocupação com os impactos que os eventos causam no meio ambiente assume um degrau institucional e formal, inclusive com as normas analisadas; tais aplicações ainda devem ser amplamente discutidas, sobretudo pela diversidade de tipos de eventos, empresas organizadoras e localidades que recebem esses eventos, de forma que essa questão incida profissionalmente no planejamento e oferta dos eventos enquanto também política de comunicação.

Devido ao próprio caráter exploratório deste trabalho, os resultados são apenas indiciais. Sugere-se que outros estudos desenvolvam aspectos aqui abordados, caso de analisar contribuições que as normas ABNT NBR ISO 20121 e ASTM E60.02 propiciaram a eventos e seus desdobramentos ambientais, ou como suportes, conteúdos, formas e instrumentos de comunicação podem ser utilizados a fim de se enquadrar ou sintonizar-se com as normas citadas. 


\section{Referências}

ANDERSSON. Tommy D.; JUTBRING, Henrik; LUNDBERG, Erik. When a music festival goes veggie: Communication and environmental impacts of an innovative food strategy. International Journal of Event and Festival Management, vol. 4 n. 3, 2013, p.224 - 235.

AVIGO, Regiane Aires. A aplicação dos princípios da sustentabilidade em eventos corporativos. XVIII Congresso de Ciências da Comunicação na Região Sudeste. Bauru-SP, 2013.

BARDIN, Laurence. Análise de conteúdo. Lisboa: Edições 70, 2004.

FONTES, N. et al. Eventos mais sustentáveis: uma abordagem ecológica, econômica, social, cultural e política. São Carlos: EdUFSCar, 2008.

FORTES, Waldyr Gutierre; SILVA, Mariângela Benine Ramos. Eventos: estratégias de planejamento e execução. São Paulo: Summus, 2011.

GÖBBELS, Math; JONKER, Jan. AA1000 and SA8000 compared: a systematic comparison of contemporary accountability standards. Managerial Auditing Journal, v. 19, n. 1, 2003, p. 54-58.

MATIAS, Marlene. Organização de eventos: procedimentos e técnicas. Barueri/ SP: Manole: 2013.

MONZONI-NETO, Mario Prestes et al. Sustentabilidade e a Copa do Mundo de 2014. Anais do SIMPOI 2011 (Simpósio de Administração da Produção, Logística e Operações Internacionais). São Paulo: FGV, 2011. 16 p.

O’BRIEN, Danny; GARDINER, Sarah. Creating sustainable mega event impacts: networking and relationship development through pre-event training. Sport Management Review, Amsterdam, v. 9, n. 1, maio 2006, p. 25-47. SACHUK, Maria Iolanda; CORREA, Tamy Carla. Ferramentas de marketing utilizadas em organização de eventos: o caso do Paraná Fashion. Gestão e Regionalidade, v. 23, nº 67, maio-ago. 2007. 


\section{Notas}

1 Fórum Eventos 2013 aborda a importância das feiras para o desenvolvimento econômico e o comércio exterior. ABEOC (Associação Brasileira de Empresa de Eventos). Website. Florianópolis-SC. 22 mar. 2014. Disponível em: http://www.abeoc.org.br/2013/03/forum-eventos-2013-aborda-a-importanciadas-feiras-para-o-desenvolvimento-economico-e-o-comercio-exterior. Acesso em: 3 fev. 2014.

2 DANTAS, Tiago. "Viagens de avião transformam Copa de 2014 em líder em emissão de poluentes". UOL São Paulo. 21/12/2013. Disponível em: http:/ / copadomundo.uol.com.br/noticias/redacao/2013/12/21/viagens-de-aviaotransformam-copa-de-2014-em-lider-em-emissao-de-poluentes.htm. Acesso em 22 dez. 2013.

3 ISO. Benefits of International Standards.Website. Genebra: International Organization for Standardization. Disponível em www.iso.org. Acesso em 7 jan. 2014.

4 ABEOC Brasil. Selo de Qualidade. Website. Florianópolis: Associação Brasileira de Empresas de Eventos. Disponível em: http://www.abeoc.org.br. Acesso em: 7 jan. 2014.

5 ABNT - ASSOCIAÇÃO BRASILEIRA DE NORMAS TÉCNICAS. ABNT NBR ISO 20121. Sistemas de Gestão para sustentabilidade de eventos. Rio de Janeiro: ABNT, 2012. 49p.

6 ASTM - AMERICAN SOCIETY FOR TESTING AND MATERIALS. ASTM E60.02. Sustentabilidade em hospitalidade. West Conshohocken: ASTM, 2012. 75p.

7 A abrangência da norma foi estimada pela quantidade de citações ou textos científicos/acadêmicos elencados pelo Google Scholar (http://scholar. google.com.br/) em 8 jan. 2014. Utilizou-se o nome da organização normativa (OKS, ou ISO, ou ASTM) conjugada com o termo "evento sustentável" ou sua expressão em inglês, totalizando 128 ocorrências para a ISO, 13 para a ASTM e nenhuma para OKS. 